\title{
PEMETAAN KERAPATAN VEGETASI MANGROVE DI SISI TENGGARA PULAU ENGGANO MENGGUNAKAN DATA CITRA SATELIT
}

\author{
Okawati Silitonga, Dewi Purnama, Eko Nofridiansyah \\ Program Studi IImu Kelautan Universitas Bengkulu \\ E-mail : ekonofridiansyah@unib.ac.id
}

Received March 2018, Accepted April 2018

\begin{abstract}
ABSTRAK
Pulau Enggano memiliki banyak potensi sumberdaya alam yang dapat dikelola, khususnya dalam bidang ekosistem mangrove, salah satu keberadaan vegetasi mangrove di Sisi Tenggara Pulau Enggano. Keberadaan hutan mangrove sangatlah penting, sebagai habitat dari berbagai macam biota, sebagai pelindung dan penahan dari intrusi air laut, sebagai perangkap sedimen, melindungi pantai dari abrasi dan merupakan salah satu penyuplai nutrisi berupa serasah pada ekosistem laut. Penelitian ini bertujuan untuk menghitung, menganalisis dan memetakan kerapatan vegetasi mangrove dan di Sisi Tenggara Pulau Enggano dari tahun 2009 dan 2016. . Kerapatan vegetasi mangrove di Sisi Tenggara Pulau Enggano dari tahun 2009 ke 2016 mengalami perubahan kerapatan. Kelas kerapatan jarang berkurang sebesar 445,34 $\mathrm{Ha}$, kerapatan sedang berkurang sebesar 88, $883 \mathrm{Ha}$ dan kerapatan lebat mengalami pertambahan luas sebesar sebesar 556,769 Ha.
\end{abstract}

Kata Kunci : Mangrove, NDVI, Penginderaan Jauh, Sisi Tenggara Pulau Enggano

\begin{abstract}
Enggano Island has many potential natural resources that can be managed, especially in the field of mangrove ecosystems, one of the existence of mangrove vegetation on the Southeast side of Enggano Island. The existence of mangrove forests is very important, as the habitat of various biota, as a protector and retainer of sea water intrusion, as a sediment trap, protect the beach from abrasion and is one of the nutrient suppliers in the form of litter on the marine ecosystemThis research aims to calculate, analyze and map the density of mangrove vegetation and on the Southeast Side of Enggano Island from 2009 and 2016. The density of mangrove vegetation on the Southeast side of Enggano Island from 2009 to 2016 has changed the density. Class density rarely decreased by 445 ,
\end{abstract}


$34 \mathrm{Ha}$, medium density was reduced by 88. $883 \mathrm{Ha}$ and dense density increased by an area of 556, $769 \mathrm{Ha}$.

Keywords : Mangrove, NDVI, Remote Sensing, Southeast Side Enggano Island

\section{PENDAHULUAN}

Pulau Enggano merupakan salah satu pulau terdepan di Indonesia yang berada di Samudra Hindia. Secara geografis, Pulau Enggano terletak pada posisi 05031'13" LS dan 102 16'00" BT. Berdasarkan administratif, Pulau Enggano merupakan sebuah kecamatan yang termasuk dalam wilayah Kabupaten Bengkulu Utara, Provinsi Bengkulu. Keseluruhan wilayah daratan Pulau Enggano terdiri dari enam desa yaitu Malakoni, Apoho, Meok, Banjarsari, Kaana dan Kahyapu (Agustini, 2014).

Pulau Enggano memiliki banyak potensi sumberdaya alam yang dapat dikelola, khususnya dalam bidang ekosistem mangrove, salah satu keberadaan vegetasi mangrove di Sisi Tenggara Pulau Enggano. Hutan Mangrove merupakan komunitas vegetasi pantai tropik yang didominasi oleh beberapa pohon mangrove yang mampu tumbuh dan berkembang pada daerah pasang surut dengan pantai berlumpur. Keberadaan hutan mangrove sangatlah penting, sebagai habitat dari berbagai macam biota, sebagai pelindung dan penahan dari intrusi air laut, sebagai perangkap sedimen, melindungi pantai dari abrasi dan merupakan salah satu penyuplai nutrisi berupa serasah pada ekosistem laut (Bengen, 2004). Oleh karena pentingnya fungsi mangrove untuk makhluk hidup maka perlu dilakukan pemetaan mangrove sebagai upaya untuk mendukung kegiatan monitoring, inventarisasi dan konservasi mangrove di Sisi Tenggara Pulau Enggano.

Teknologi yang mudah, murah dan cepat untuk monitoring mangrove adalah dengan menggunakan teknologi penginderaan jauh melalui perekaman citra satelit. Penginderaan jauh dapat diartikan sebagai teknologi untuk mengidentifikasi suatu obyek dipermukaan bumi tanpa melalui kontak langsung dengan obyek tersebut. Adanya resolusi temporal (perulangan) sehingga dapat digunakan untuk keperluan monitoring, cakupannya yang luas dan mampu menjangkau daerah yang terpencil, bentuk datanya digital sehingga dapat digunakan untuk berbagai keperluan (Lillesand dan Kiefer, 1990 dalam Indica dkk., 2010)

Beberapa penelitian tentang mangrove telah dilakukan di Sisi Tenggara Pulau Enggano, seperti: Agustini (2014) meneliti tentang Struktur Komunitas Ekosistem Mangrove Didesa Kahyapu Pulau Enggano, Fitriana (2016) tentang Analisis Kesesuaian Ekowisata Mangrove Desa Kahyapu Pulau Enggano, Pratama (2016) tentang Kajian Kondisi Ekologi Ekosistem Mangrove Di Teluk Harapan Pulau Enggano. Penelitian sebelumnya hanya terdiri dari beberapa stasiun saja belum ada penelitian tentang kepastian kerapatan hutan mangrove secara keseluruhan di Sisi Tenggara Pulau Enggano. Oleh karena itu perlu 
dilakukan pengamatan dari tahun 2009 ke 2016 untuk memonitoring kondisi ekosistem mangrove selama 7 tahun terakhir di Sisi Tenggara Pulau Enggano dengan menggunakan bantuan satelit yang dapat mempermudah dalam melakukan penelitian. Penelitian ini bertujuan untuk menghitung, menganalisis dan memetakan distribusi luasan dan kerapatan vegetasi mangrove dan di Sisi Tenggara Pulau Enggano dari tahun 2009 dan 2016. Hasil penelitian di harapkan dapat menjadi informasi yang efektif dalam inventarisasi dan monitoring mangrove sebagai dasar perencanaan dan pengambilan keputusan termasuk dalam pengelolaan hutan mangrove.

\section{MATERI DAN METODE}

\section{Waktu dan Lokasi Penelitian}

Pengolahan citra telah dilaksanakan dari bulan Februari sampai bulan Maret 2017 dan survey lapang dilaksanakan pada bulan April dan Juni 2017 yang tersebar 28 titik di Sisi Tenggara Pulau Enggano, Kecamatan Enggano, Kabupaten Bengkulu Utara, Provinsi Bengkulu.

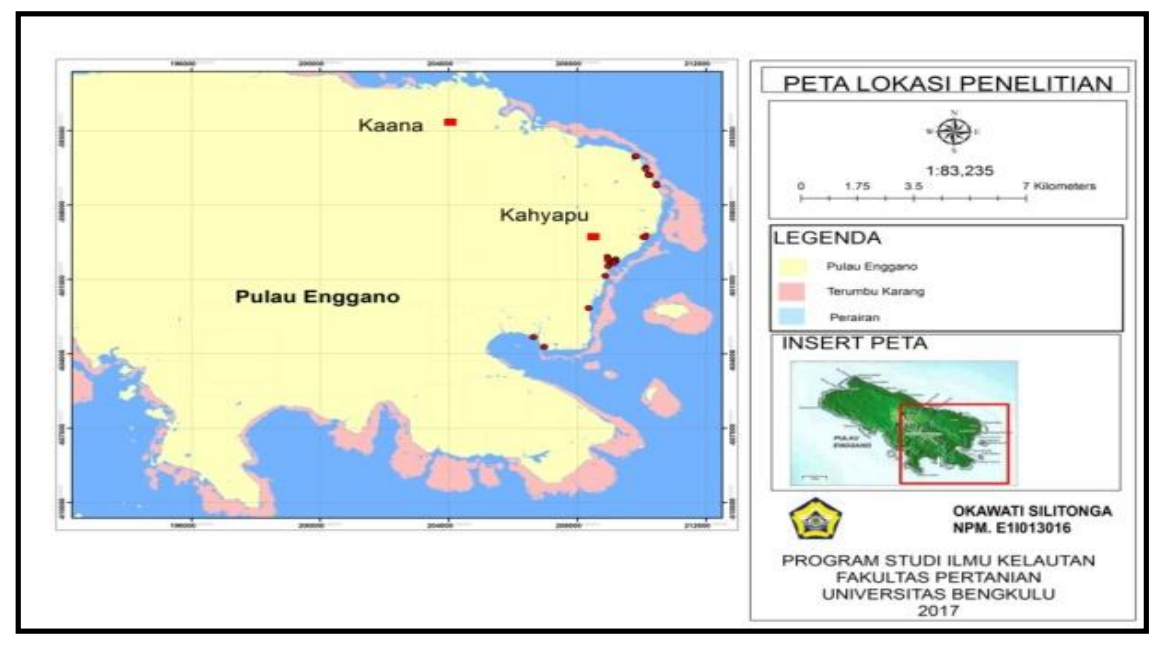

Gambar 1. Peta Lokasi Penelitian

\section{Metode Pengumpulan Data}

Penelitian ini menggunakan metode survey yaitu dengan observasi (mengamati lingkungan), wawancara dan dokumentasi. Bentuk pengumpulan yaitu, Data primer berupa data yang didapatkan dari kegiatan survey lapangan/groundcheck yaitu data lapangan berupa data kerapatan dan data lapangan yang dilakukan untuk memperoleh uraian umum dari lokasi, mencari /mendapatkan penutup lahan dan meningkatkan informasi yang tidak diperoleh dari interpretasi pertama citra satelit dan test (checking) serta verifikasi tentang kebenaran interpretasi serta hasil klasifikasi. 


\section{Prosedur Kerja}

\section{Distribusi Luasan dan Kerapatan Vegetasi Mangrove}

\section{Perolehan data citra satelit}

Citra satelit diperoleh dari Lembaga Penerbangan dan Antariksa Nasional (LAPAN) dalam bidang Pusat dan Teknologi Data dengan kode wilayah 125/64.

\section{Import data dan penggabungan band}

Format data citra yang digunakan dalam penelitian ini berekstensi ( ${ }^{*}$.tif) dan ( ${ }^{*}$.img), agar data citra dapat dibaca dan diproses oleh program ER MAPPER 7.0 harus dikonversi dalam format data raster (*.ers) yang dilakukan melalui proses import data kemudian melakukan penggabungan band untuk setiap citra (Ridho, 2006).

\section{Pemulihan Citra}

Proses pemulihan citra terdiri dari koreksi radiometrik dan geometric. Koreksi radiometrik bertujuan untuk meperbaiki nilai-nilai piksel yang tidak sesuai dengan nilai pantula atau pancaran spektral objek yang sebenarnya sedangkan koreksi geometrik bertujuan untuk memperbaiki kesalahan posisi atau letak objek yang terekam pada citra disebabkan adanya distorsi geometrik seperti kesalahan instrumen berupa sistem optik, mekanisme penyiaman, distorsi panoramik berupa sudut pandang sensor terhadap bumi, rotasi bumi, dan ketidakstabilan wahana (Laremba, 2014).

\section{Color Composit (RGB) dan Pemotongan Citra (Cropping).}

Color composite yang digunakan untuk Citra Landsat 5 adalah Band 453 dan Landsat 8 OLI adalah 564. Pemotongan citra dilakukan untuk membatasi daerah penelitian sehingga memudahkan analisis pada komputer. Selain itu, pemotongan citra akan mengurangi kapasitas memori sehingga memudahkan pada proses pengolahan data citra tersebut (LAPAN, 2015).

\section{Penajaman Citra (Digital Enhancement)}

Teknik ini dapat digunakan untuk mempertajam kenampakan objek secara keseluruhan mempertajam tepian, menghaluskan noise/gangguan, memunculkan spesifik area tertentu di citra. 


\section{Klasifikasi Pada Citra}

Proses klasifikasi dilakukan untuk mengelompokkan objek atau kenampakan yang homogen yaitu dengan menempatkan piksel-piksel ke dalam suatu kelas menurut kesamaan nilai digital dari tiap piksel (Opa, 2010). Pada penelitian ini digunakan klasifikasi tak terbimbing (unsupervised classification) dengan dukungan data lapangan. Dari hasil klasifikasi pada citra maka akan didapatkan penutupan lahan dan luasan vegetasi mangrove di Sisi Tenggara Pulau Enggano.

\section{Indeks Vegetasi}

Salah satu indeks vegetasi adalah dengan metode Normalized Difference Vegetation Index (NDVI) yang bertujuan untuk menentukan tingkat kerapatan kanopi mangrove. Formula NDVI didasarkan pada reflektansi dari objek penginderaan jauh dalam saluran spektrum merah dan inframerah dekat yaitu untuk Landsat 5 adalah band 3 dan band 4 dan untuk Landsat 8 adalah band 5 dan band 4 (Widodo, 2014). Dari pengolahan indeks vegetasi (NDVI) maka akan didapatkan peta distribusii kerapatan mangrove di Desa Kahyapu.

\section{Penggabungan (Overlay) klasifikasi lahan dan indeks vegetasi}

Citra penutupan lahan hasil klasifikasi tak terbimbing dapat dioverlay dengan citra hasil analisis indeks vegetasi (NDVI) untuk memperlihatkan distribusi mangrove menurut kerapatannya. ArcGis 10.2 dapat menampilkan distribusi mangrove di Sisi Tenggara Pulau Enggano menurut kerapatannya dapat ditampilkan dalam bentuk peta tematik.

\section{Pengambilan Data Kerapatan Mangrove di Lapangan}

Pengambilan data lapang (ground check) dilakukan sebagai satu kegiatan yang penting dalam interpretasi citra satelit. Kegiatan ini memberikan penjelasan mengenai kondisi ekosistem sebenarnya di lapangan. Kegiatan ground check terdiri dari penyesuaian hasil distribusi dan kerapatan mangrove dari citra satelit dengan data kerapatan serta penutupan tajuk mangrove dilapangan dimana pengukuran posisi dengan Global Positioning System (GPS).

\section{Analisis Data}

\section{Normalized Difference Vegetation Index (NDVI)} berikut:

Formula NDVI menurut Danoedoro (1996) dapat diuraikan sebagai

$\mathrm{NDVI}=\frac{N I R-R E D}{N I R+R E D}$ 
NIR = Nilai spektral saluran Near Infrared

RED = Nilai spektral saluran red

Untuk menentukan nilai kerapatan tajuk mangrove menggunakan hasil perhitungan dari NDVI. Kemudian nilai kelas NDVI tersebut diklasifikasikan ulang (reclass) menjadi 3 kelas, yaitu kerapatan jarang, sedang dan lebat.

Berikut adalah tabel penilaian tingkat kerapatan tajuk mangrove berdasarkan nilai NDVI:

Tabel 1. Kriteria Tingkat Kerapatan Tajuk

\begin{tabular}{ll}
\hline Nilai NDVI & Tingkat Kerapatan Tajuk \\
\hline $0.43 \leq \mathrm{NDVI} \leq 1,00$ & Lebat \\
$0,33 \leq \mathrm{NDVI} \leq 0,42$ & Sedang \\
$-1.0 \leq \mathrm{NDVI} \leq 0.32$ & Jarang \\
\hline
\end{tabular}

Sumber: Departemen Kehutanan (2005)

\section{Kerapatan Mangrove}

Analsis data yang digunakan untuk mengetahui kerapatan mangrove pada saat survey dilapangan menurut Rancangan Standar Nasional Indonesia (2011) dilakukan dengan menggunakan rumus berikut:

Kerapatan $=\frac{\text { Jumlah Individu (Pohon) }}{\text { Luas Seluruh Petak }}$

\section{Presentase Tutupan Mangrove}

Konsep dari analisis ini adalah pemisahan pixel langit dan tutupan vegetasi, sehingga presentase jumlah pixel tutupan vegetasi mangrove dalam analisis gambar biner (Ishida, 2004 ; Chiannucci et al., 2014). Presentase tutupan mangrove dihitung dengan rumus

$\%$ tutupan mangrove $=\frac{P 255}{\Sigma P} \times 100 \%$

\section{Uji Akurasi}

Dalam suatu penelitian yang menggunakan data dan metode tertentu perlu dilakukan uji ketelitian kembali karena hasil uji ketelitian tersebut sangat mempengaruhi besarnya kepercayaan pengguna terhadap setiap jenis data maupun metode analisisnya. Untuk mengetahui 
tingkat akurasi dari hasil klasifikasi digunakan metode uji ketelitian klasifikasi confusion matriks (Tabel 2).

Tabel 2. Bentuk matriks kesalahan (confusion matriks)

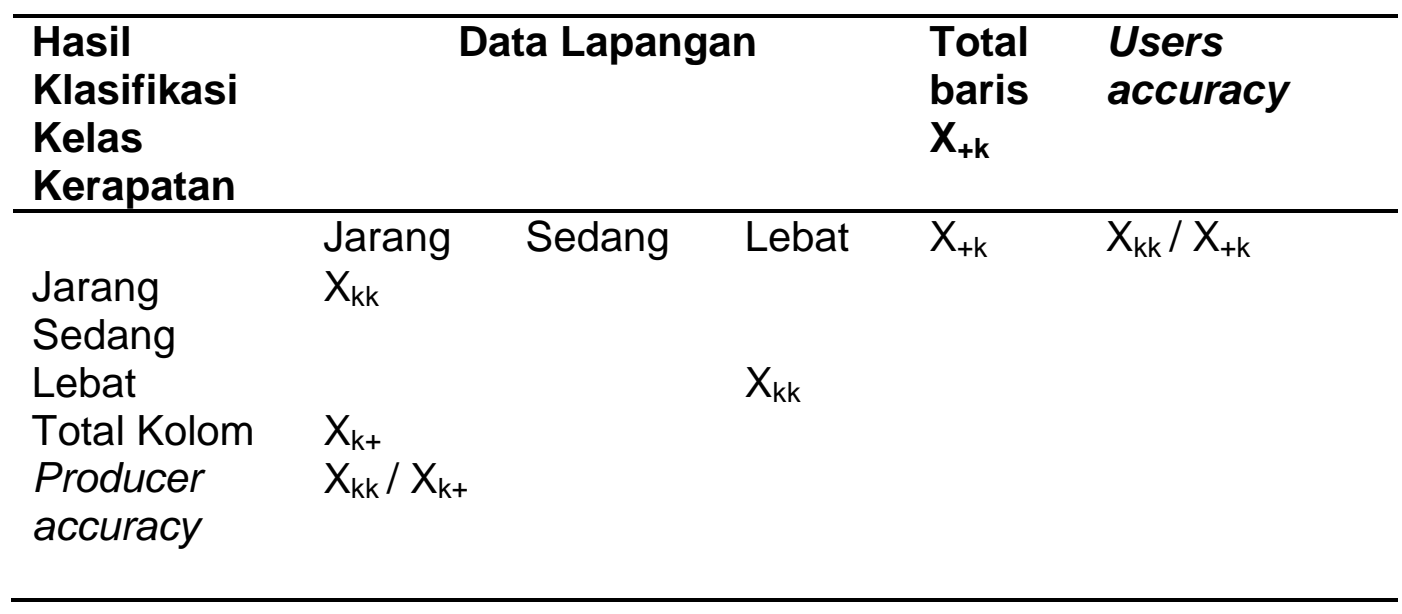

Uji ketelitian yang dihitung adalah overall accuracy, producer's accuracy dan user's accuracy. Overall accuracy adalah persentase dari piksel-piksel yang terkelaskan dengan tepat, producer's accuracy adalah peluang rata-rata (\%) suatu piksel yang menunjukkan sebaran dari masing-masing kelas yang telah diklasifikasi di lapangan, dan user's accuracy adalah peluang rata-rata (\%) suatu piksel secara aktual yang mewakili kelas-kelas tersebut (Arhatin, 2007).

\section{HASIL DAN PEMBAHASAN}

\section{Analisis Citra Secara Visual}

Analisis citra secara visual dilakukan dapat mempermudah mengenali objek permukaan bumi. Kenampakan visual didapatkan dari pembuatan citra warna komposit dengan memasukkan kanal-kanal tertentu kedalam filter merah, hijau dan biru (RGB). Menurut Suwargana (2008) komposit warna yang digunakan untuk mengidentifikasi mangrove pada Landsat TM adalah RGB 453 hal ini dikarenakan RGB 453 merupakan komposit dengan nilai kekontrasan tinggi. Purwanto $d k k$, (2014) pada citra satelit Landsat 8 digunakan komposit RGB 564 di mana ketiga band tersebut termasuk dalam kisaran spektrum tampak dan inframerah - dekat dan mempunyai panjang gelombang yang sesuai dengan panjang gelombang band 4 , band 5 dan band 3 pada citra satelit Landsat 5 TM. Dari citra komposit tersebut kemudian dilakukan uji penajaman dan pemfilteran untuk memperjelas kenampakan pada citra, terutama pada objek hutan mangrove.. Dari hasil komposit dilakukan penajaman dan pemfilteran kenampakan pada citra. Identifikasi pada citra komposit RGB 453 Tahun 2009 dan 564 Tahun 2016 (Gambar 1) dengan warna vegetasi mangrove adalah kuning kecoklatan. 


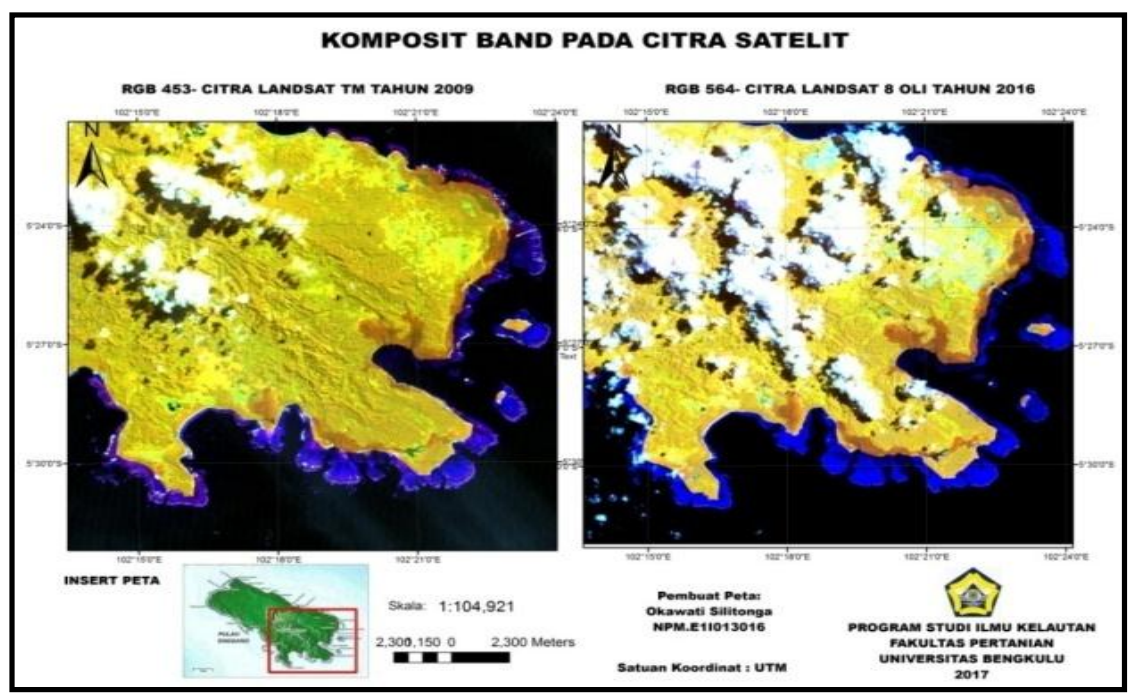

Gambar 2. Komposit band pada citra satelit

\section{Distribusi Kerapatan Vegetasi Mangrove}

Indeks vegetasi merupakan kombinasi matematis antara band red dan band NIR yang telah lama digunakan untuk memgidentifikasi keberadaan dan kondisi vegetasi (Lillesand and Kiefer, 1997). NDVI memiliki rentang nilai -1 (minus 1) hingga 1.0 (positif 1). Nilai NDVI yang menunjukkan tingkat kesehatan vegetasi yang baik apabila nilai NDVI berada pada nilai 0.1-0.7 (Prahasta, 2008) yang mewakili vegetasi berada pada rentang 0.1 hingga 0.7 .

Pada penelitian ini nilai NDVI pada citra Landsat 5 (Tahun 2009) memiliki nilai NDVI minimum sebesar 0.02 dan nilai NDVI maksimum 0.85 dan pada citra Landsat 8 (Tahun 2016), nilai NDVI minimum adalah 0.01 dan nilai NDVI maksimum adalah 0.91. Selanjutnya dilakukan klasifikasi kerapatan yang terbagi dalam 3 kelas kerapatan tajuk, yaitu: jarang, sedang dan lebat (Departemen Kehutanan, 2005). Dari keadaan hasil kelas kerapatan yang didapatkan dari indeks vegetasi (NDVI) maka dapat ditentukan luasan vegetasi mangrove di Sisi Tenggara Pulau Enggano seperti pada Tabel 3.

Tabel 3. Hasil perhitungan luasan kerapatan dan persentase tahun 2009 dan 2016

\begin{tabular}{lllll}
\hline Kelas Kerapatan & Tahun 2009 & \multicolumn{3}{l}{ Tahun 2016 } \\
\cline { 2 - 5 } & Luas $(\mathrm{Ha})$ & $\%$ & Luas $(\mathrm{Ha})$ & $\%$ \\
\hline Jarang & 562.36 & 49 & 117.023 & 10 \\
Sedang & 241.012 & 21 & 152.129 & 13 \\
Lebat & 344.304 & 30 & 901.073 & 77 \\
\hline
\end{tabular}


Pada Tabel 3 dapat dilihat perbandingan luasan serta persentase kerapatan mangrove di Sisi Tenggara Pulau Enggano. Pada tahun 2009 kerapatan jarang memiliki luas $562,363 \mathrm{Ha} \mathrm{(49 \% )} \mathrm{berkurang} \mathrm{menjadi}$ $117,023 \mathrm{Ha} \mathrm{(10 \% )} \mathrm{pada} \mathrm{tahun} \mathrm{2016,} \mathrm{kerapatan} \mathrm{sedang} \mathrm{pada} \mathrm{tahun} 2009$ memiliki luas $241,012 \mathrm{Ha}(21 \%)$ berkurang menjadi 152,129 Ha (13\%) pada tahun 2016 selanjutnya kerapatan lebat pada tahun 2009 memiliki luas 344,304 Ha (30\%) bertambah menjadi 901,073 Ha (77\%) pada tahun 2016. Berkurangnya luasan kerapatan jarang dan sedang pada tahun 2016 terjadi bukan karena mengalami kerusakan tetapi berpindahnya kerapatan mangrove dari kerapatan jarang ke kekerapatan sedang dan kerapatan sedang ke kekerapatan lebat. Hal ini menunjukkan bahwa kondisi vegetasi mangrove di Sisi Tenggara Pulau Enggano dari tahun ke-tahun bertambah kerapatannya. Hal ini menunjukkan indikasi terjaganya kelestarian dan belum adanya ancaman pada ekosistem mangrove di Sisi Tenggara Pulau Enggano baik secara alami maupun antropogenik. Hasil analisis pada kelas kerapatan mangrove pada tahun 2009 dapat dilihat pada Gambar 3.

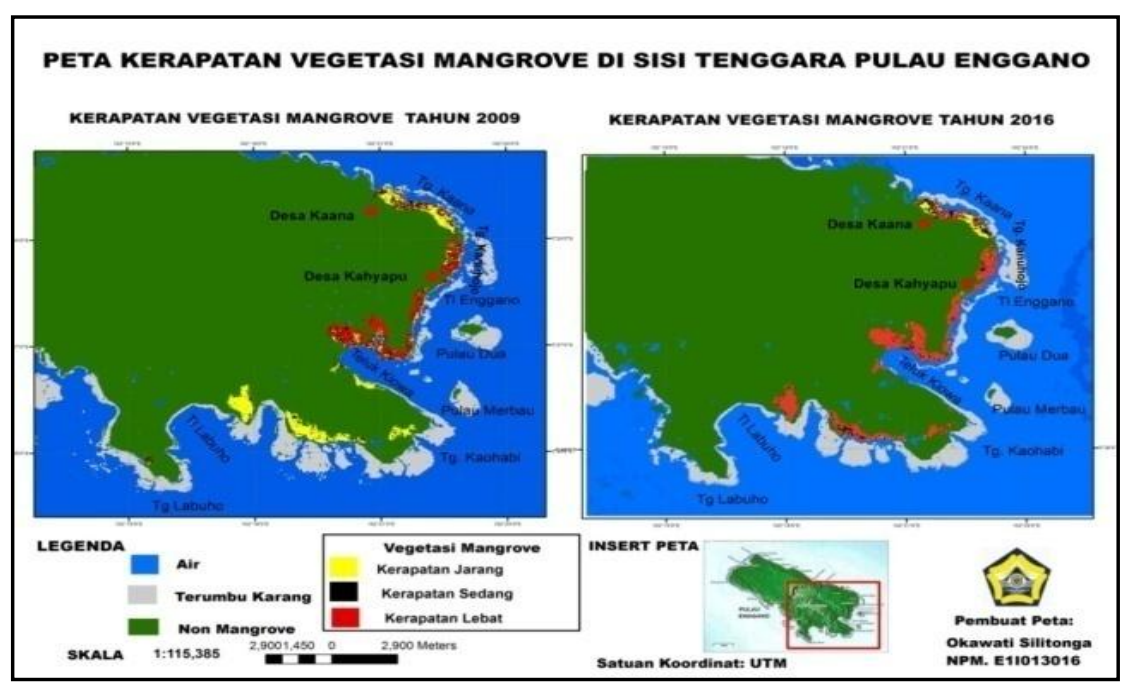

Gambar 3. Peta kerapatan vegetasi mangrove Tahun 2009 dan 2016

Gambar 3 menunjukkan perubahan kerapatan mangrove di setiap wilayah seperti pada Teluk Labuho dan Tanjung Kaohabi pada tahun 2009 masih dominan terhadap kelas kerapatan jarang sedangkan pada tahun 2016 telah mengalami perubahan menjadi kerapatan lebat. Didaerah Teluk Kiowa dan Teluk Enggano tahun 2009 kerapatan lebat, kerapatan jarang dan kerapatan sedang masih terlihat jelas sedangkan pada tahun 2016 telah berubah menjadi kerapatan lebat.

Secara keseluruhan kerapatan lebat dominan pada tahun 2016, kecuali Tanjung Kaana. Sedikitnya perubahan diduga karena pada hasil groundcheck tidak ditemukan adanya kerusakan vegetasi mangrove. Hal ini diduga karena kondisi substrat di Tanjung Kaana secara visual adalah 
pantai berpasir yang berhadapan dengan laut dan tidak memiliki muara sungai yang besar.

Secara keseluruhan kerapatan lebat dominan pada tahun 2016, kecuali Tanjung Kaana. Sedikitnya perubahan diduga karena pada hasil groundcheck tidak ditemukan adanya kerusakan vegetasi mangrove. Hal ini diduga karena kondisi substrat di Tanjung Kaana secara visual adalah pantai berpasir yang berhadapan dengan laut dan tidak memiliki muara sungai yang besar.

Menurut Dahuri (2004) tumbuhan mangrove dapat tumbuh secara optimal pada kawasan pesisir yang mempunyai muara sungai besar dan delta yang aliran lainya banyak mengandung lumpur. Selanjutnya yang menyebabkan dominannya kerapatan jarang di Tanjung Kaana karena hampir sebagian besar mangrove memiliki formasi depan yang berupa pantai berpasir dan ditutupi oleh substrat patahan karang. Selain itu daerah Tanjung Kaana memiliki kondisi perairan dengan ombak yang tinggi jika dibandingkan dengan lokasi lainya. Menurut Noor (2006) mangrove banyak dijumpai diwilayah pesisir yang yang terlindung dari gempuran ombak. Hal ini sesuai dengan pendapat Kusmana (2007) yang menjelaskan bahwa gelombang dapat merubah struktur dan fungsi mangrove. Pada lokasi yang memiliki gelombang dan arus yang cukup tinggi biasanya akan mengalami abrasi sehingga terjadi pengurangan luasan mangrove. Menurut FAO (1983) menjelaskan bahwa gelombang juga berpengaruh pada distribusi spesies semaian mangrove yang terbawa gelombang. Jika dilihat dari segi geologi, Sisi Tenggara Pulau Enggano terdapat pulau-pulau kecil seperti Pulau Dua, Pulau Bangkai dan Pulau Merbau sehingga gelombang laut yang datang dari Samudera Hindia tidak langsung mengarah kearah vegetasi mangrove selain itu masih lengkapnya adanya ekosistem terumbu karang dan padang lamun sehingga gelombang dan arusnya tenang. Menurut Kusmana (1997) Gelombang dan arus dapat merubah struktur dan fungsi mangrove. Pada lokasi yang memiliki gelombang dan arus yang cukup tinggi biasanya akan mengalami abrasi sehingga terjadi pengurangan luasan mangrove sehingga terhindar dari erosi yang dapat merubah struktur ekosistem mangrove.

Perubahan kelas kerapatan vegetasi mangrove dari tahun 2009 ke 2016 dapat terjadi adanya penambahan jumlah populasi mangrove. Selain itu bisa juga terjadi karena tajuk mangrove yang semakin lebat.

Hasil dari pengolahan citra dan data lapangan menunjukkan bahwa kondisi vegetasi mangrove dari tahun 2009 ke 2016 semakin lestari. Menurut Zamdial (2016), pada awalnya untuk tetap menjaga kelestarian ekosistem hutan mangrove di Pulau Enggano, masyarakat bersandar pada kekuatan kearifan lokal yaitu "Kerapatan Adat Suku-Suku". Selain itu masyarakat enggano melakukan kesepakatan bersama yaitu sejak Tahun 2009 adanya Peraturan Desa (Perdes) yang khusus dimaksudkan untuk memberi perlindungan kepada ekosistem hutan mangrove. Dengan adanya peraturan desa diduga berpengaruh pada pertambahan luasan mangrove di Sisi Tenggara Pulau Enggano dari tahun 2009 ke 2016. 
Pemahaman dan kesadaran yang sangat kuat dikalangan masyarakat menjadikan kondisi ekosistem hutan mangrove di Pulau Enggano tetap terjaga dan lestari. Masyarakat telah menjadikan ekosistem mangrove menjadi sumber penghidupan karena sebagian besar masyarakat Pulau Enggano hidup dengan mencari kepiting bakau (Scylla serrata), lokan (mangrove clam), dan berbagai jenis ikan dan burung yang berada di kawasan ekosistem hutan mangrove Pulau Enggano.

Hasil NDVI berdasarkan kelas kerapatan jarang, sedang dan lebat disesuaikan dengan penentuan lokasi groundcheck. Titik koordinat hasil NDVI disesuaikan dengan lokasi di lapangan. Hasil dari kerapatan mangrove (pohon/ha) dan persentase tajuk mangrove (\%) dirata-ratakan berdasarkan kategori kerapatan dan kategori kerapatan disesuaikan dengan Kepmen LH No. 210 Tahun 2004 seperti pada Tabel 4.

Tabel 4. Rata-rata Kerapatan dan Penutupan Vegetasi Mangrove Berdasarkan Hasil Groundcheck

\begin{tabular}{lcc}
\hline Kategori & $\begin{array}{c}\text { Rata-rata Kerapatan } \\
\text { (pohon/ha) }\end{array}$ & $\begin{array}{c}\text { Rata-rata Persentase } \\
\text { Tajuk Mangrove (\%) }\end{array}$ \\
\hline Kerapatan Jarang & 446 & 30.44 \\
Kerapatan Sedang & 1098 & 62.19 \\
Kerapatan Lebat & 1555 & 81.14 \\
\hline
\end{tabular}

Hasil dari kerapatan pohon dan presentase tutupan tajuk mangrove di lapangan menunjukkan bahwa berubahnya kerapatan mangrove dari tahun 2009 ke 2016 terjadi bukan hanya karena bertambahnya populasi mangrove tetapi juga karena tajuk mangrove yang semakin lebat. Untuk mengetahui tingkat ketelitian dalam pengolahan data maka dilakukan uji akurasi antara data lapangan dengan data hasil kelas kerapatan mangrove seperti pada Tabel 5 .

Tabel 5. Uji Akurasi

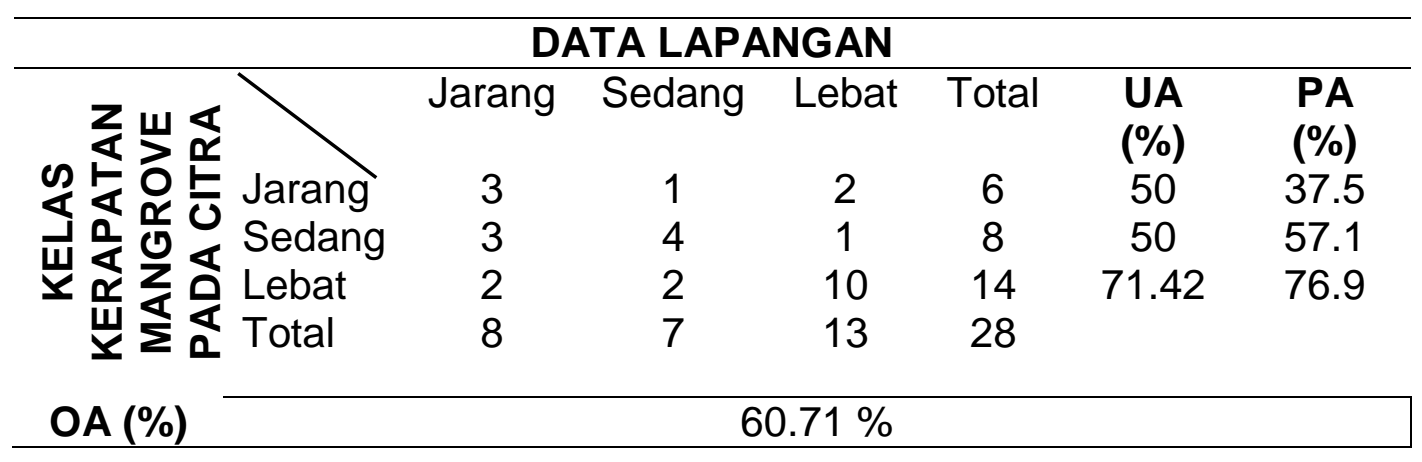

Keterangan :UA : User's accuracy

PA : Producer accuracy

OA : Overall accuracy 
Producer's accuracy dan user's accuracy tertinggi diperoleh pada kelas kerapatan lebat sebesar $76,9 \%$ dan 71,42 dan terendah berada pada kelas kerapatan jarang dengan niali 37,5 dan $50 \%$. Tingkat akurasi klasifikasi keseluruhan dapat dilihat dari overall accuracy yaitu sebesar $60,71 \%$. Menurut Prasetyo (2005) hasil akurasi dapat diterima apabila nilai akurasi lebih besar atau sama dengan $60 \%$. Hal ini menunjukkan tingkat akurasi hasil klasifikasi kelas kerapatan dengan data lapangan dapat diterima sebesar $60,71 \%$ dan cukup memadai.

\section{KESIMPULAN}

Kerapatan vegetasi mangrove di Sisi Tenggara Pulau Enggano dari tahun 2009 ke 2016 mengalami perubahan kerapatan. Kelas kerapatan jarang berkurang sebesar $445,34 \mathrm{Ha}$, Kerapatan sedang berkurang sebesar $88,883 \mathrm{Ha}$ dan kerapatan lebat mengalami pertambahan luas sebesar sebesar 556, $769 \mathrm{Ha}$. Secara keseluruhan kondisi vegetasi mangrove di Sisi Tenggara Pulau Enggano masih dalam kondisi yang lestari dan terjaga.

\section{DAFTAR PUSTAKA}

Agustini, N.T. 2014. Struktur Komunitas Ekosistem Mangrove Didesa Kahyapu Pulau Enggano. Skripsi. Fakultas Pertanian. Universitas Bengkulu. Bengkulu.

Arhatin, R.E. 2007. Pengkajian Algoritma Indeks Vegetasi Dan Metode Klasifikasi Mangrove Dari Data Satelit Landsat-5 Dan Landsat-7 ETM+ (Studi Kasus di Kabupaten Berau, Kaltim). [Thesis]. Program Pascasarjana IPB. Bogor

Bengen, G.D. 2004. Sinopsis Ekosistem dan Sumberdaya Alam Pesisir. Pusat Kajian Sumberdaya Pesisir dan Lautan-Institut Pertanian Bogor. Bogor, Indonesia.

Dahuri Rokhmin, dkk. 2004. Sumber Daya Wilayah Pesisir dan Laut. Jakarta : PT. Pradnya Paramita.

Danoedoro, P. 1996. Pengolahan Citra Digital Teori dan Aplikasinya. Fakultas Geografi Universitas Gadjah Mada, Yogyakarta.

Departemen Kehutanan. 2005. Pedoman Inventarisasi dan Identifikasi Lahan Kritis Mangrove. Direktorat Jenderal Rehabilitasi Lahan dan Perhutanan Sosial, Jakarta.

Fitriana, D. 2016. Analisis Kesesuaian Ekowisata Mangrove Desa Kahyapu Pulau Enggano. Skripsi. Program Studi Ilmu Kelautan. Fakultas Pertanian. Universitas Bengkulu, Bengkulu. 
Indica, M, Ulqodry, T., dan Hendri, M. 2010. Perubahan Luasan Mangrove dengan Menggunakan Teknik Penginderaan Jauh Di Taman Nasional Sembilang Kabupaten Banyuasin Provinsi Sumatera Selatan. Maspari Journals. 02. 77-81.

Ishida, M. 2004. Automatic Thresholding for Digital Hemispherical Photography. Canadian Journal of Forest Research. 34: 22082216.

Kusmana, C. 1997. Metode Survey Vegetasi. PT. Penerbit Institut Pertanian Bogor; Bogor.

LAPAN. 2015. Pedoman Pengolahan Data Penginderaan Jauh Landsat 8 Untuk Mangrove. Pusat Pemanfaatan Penginderaan Jauh, Jakarta Timur.

Laremba, S. 2014. Sebaran dan Kerapatan Mangrove di Teluk Kota Kendari Sulawesi Tenggara. Skripsi. Fakultas IImu Kelautan dan Perikanan, Universitas Hasanuddin, Makassar.

Lillesand, T.M., dan Kiefer, R.W., 1997, Penginderaan Jauh dan Interpretasi Citra ( Terjemahan ), Yogyakarta : Gadjah Mada University Press, Universitas Gadjah Mada Yogyakarta.

Opa, T.E., 2010. Analisis Perubahan Luas Lahan Mangrove Di Kabupaten Pohuwato Provinsi Gorontalo Dengan Menggunakan Citra Landsat. Jurnal Perikanan dan Kelautan. VI (2). 79-82.

Prahasta, Eddy. 2008. Remote Sensing Praktis Pengindraan Jauh \& Pengolahan Citra Digital Dengan Perangkat Lunak ER Mapper. Bandung: CV. Informatika

Pratama, D. 2016. Kajian Kondisi Ekologi Ekosistem Mangrove Di Teluk Harapan Pulau Enggano. Skripsi. Program Studi Ilmu Kelautan. Fakultas Pertanian. Universitas Bengkulu, Bengkulu.

Purwanto, A., D., Wikanti Asriningrum., Gatot Winarso., Ety Parwati. 2014. Analisis Sebaran dan Kerapatan Mangrove Menggunakan Citra Landsat 8 Di Segara Anakan, Cilacap. Jurnal Seminar Nasional Penginderaan Jauh. 232-242.

Rancangan Standar Nasional-3. 2011. Survei dan Pemetaan Mangrove. Cibinong, 28 Februari 2011. 
Ridho, M.R., Hartoni, dan Sari, S.P. 2006. Analisis Perubahan Luasan Mangrove di Pantai Timur Ogan Komering llir (OKI) Provinsi Sumatera Selatan Menggunakan Data Citra Landsat TM. Jurnal Pengelolaan Lingkungan dan Sumberdaya Alam. IV (2) : 11-18.

Suwargana. 2008. Analisis Perubahan Hutan Mangrove Menggunakan Data Penginderaan Jauh Di Pantai Bahagia, Muara Gembong, Bekasi. Jurnal Penginderaan Jauh. Vol (5): 54-74.

Widodo, E. Y. W. 2014. Perubahan Kondisi Mangrove Antara Tahun 1992011 Di Pesisir Kecamatan Bungoro Kabupaten Pangkep. Skripsi. Fakultas IImu Kelautan dan Perikanan. Universitas Hasanuddin, Makassar.

Zamdial. 2016. Lestarinya Hutan Mangrove Pulau Enggano, Bengkulu. Jurnal Warta Konservasi Lahan Basah. 24 (2) : 2. 